\title{
A Phase II Evaluation of a 3-Hour Infusion of Paclitaxel, Cisplatin, and 5-Fluorouracil in Patients With Advanced or Recurrent Squamous Cell Carcinoma of the Head and Neck
}

\section{Southwest Oncology Group Study 0007}

\author{
Francis P. Worden, MD ${ }^{1}$ \\ James Moon, $\mathrm{MD}^{2}$ \\ Wolfram Samlowski, $\mathrm{MD}^{3}$ \\ Joseph I. Clark, $\mathrm{MD}^{4}$ \\ Shaker R. Dakhil, MD ${ }^{5}$ \\ Stephen Williamson, MD ${ }^{6}$ \\ Susan G. Urba, MD ${ }^{1}$ \\ John Ensley, MD ${ }^{7}$ \\ Maha H. Hussain, MD ${ }^{1}$ \\ and Southwest Oncology Group, \\ the Head and Neck Working Group
}

\footnotetext{
${ }^{1}$ Department of Internal Medicine, Division of Medical Oncology, University of Michigan, Ann Arbor, Michigan.

${ }^{2}$ Department of Internal Medicine, Division of Medical Oncology, Southwest Oncology Group Statistical Center, Seattle, Washington.

${ }^{3}$ Department of Internal Medicine, Division of Medical Oncology, Wayne State University Medical Center, Detroit, Michigan.

${ }^{4}$ Department of Internal Medicine, Division of Medical Oncology, Loyola University Stritch School of Medicine, Maywood, Illinois. ${ }^{5}$ Department of Internal Medicine, Division of
Medical Oncology, Wichita Community Clinical
Oncology Program, Wichita, Kansas.

${ }^{6}$ Department of Internal Medicine, Division of Medical Oncology, University of Kansas Medical Center, Kansas City, Missouri.

${ }^{7}$ Department of Internal Medicine, Division of Medical Oncology, University of Utah Health Science Center, Salt Lake City, Utah.
}

Presented at the Southwest Oncology Group 2004 Spring Meeting, Huntington Beach, California, May 1, 2004; the 39th Annual Meeting of the American Society of Clinical Oncology, New Orleans, Louisiana, June 16, 2004; the 6th International Conference on Head and Neck Cancer Washington, DC, August 9, 2004; and the Third International Chicago Symposium on Malignan-

\begin{abstract}
BACKGROUND. Previous data from an institutional pilot study in patients with advanced or recurrent squamous cell carcinoma of the head and neck (SCCHN) who received treated a combined chemotherapy regimen of paclitaxel, cisplatin, and 5-fluorouracil indicated an overall response rate of $60 \%$ and a median survival of 6 months. To validate these results and to determine the feasibility of this combination, a Phase II study was conducted by the Southwest Oncology Group (SWOG S0007).
\end{abstract}

METHODS. Patients with advanced or recurrent SCCHN were eligible if they had received 1 previous regimen of induction/adjuvant chemotherapy or no prior systemic therapy. Patients received treatment with paclitaxel $\left(135 \mathrm{mg} / \mathrm{m}^{2}\right.$ on Day 1), followed by cisplatin $\left(75 \mathrm{mg} / \mathrm{m}^{2}\right.$ on Day 1), and 5 -fluorouracil (1000 mg/ $\mathrm{m}^{2}$ per day as a 96-hour continuous infusion on Days 1-4) every 21 days.

RESULTS. Seventy-six patients received a combined total of 286 cycles of chemotherapy. Sixty-nine patients were evaluable for response. There were $5 \mathrm{com}-$ plete responses $(7 \%)$ and 23 partial responses (33\%) partial responses, for an overall response rate of $41 \%$. The median progression-free survival was 4 months, and the median overall survival was 10 months. Six treatment-related deaths were documented, including deaths in 2 patients who had a Zubrod PS of 2. Grade 3 or 4 neutropenia (according to National Cancer Institute Common Toxicity Criteria [version 2.0]) was observed in $47 \%$ of patients. Other Grade 3 or 4 adverse events included mucositis (34\% of patients), nausea (20\% of patients), anemia ( $9 \%$ of patients), and neuropathy ( $8 \%$ of patients).

CONCLUSIONS. The combination of paclitaxel, cisplatin, and 5-fluorouracil had efficacy similar to that of standard treatment regimens in patients with advanced or recurrent SCCHN but with increased toxicity. Cancer 2006;107:319-27.

(c) 2006 American Cancer Society.

KEYWORDS: cisplatin, dose response evaluation, 5-fluorouracil, head and neck squamous cell carcinoma, paclitaxel, Response Evaluation Criteria in Solid Tumors.

cies of the Chest and Head and Neck Cancer, Chicago, Illinois, October 9, 2004.

We thank Judy Grossi, University of Michigan, for support with data management.

Address for reprints: Francis P. Worden, MD, Department of Hematology/Oncology, University of Michi- gan, 1500 E. Medical Center Drive, C361 MIB 0848, Ann Arbor, Ml 48109-0848; Fax: (734) 647-8792; E-mail: fworden@umich.edu

Received November 2, 2005; revision received March 8, 2006; accepted March 17, 2006. 
$\mathbf{R}$ ecurrent squamous cell carcinoma of the head and neck (SCCHN) is fatal uniformly and responds poorly to chemotherapy. ${ }^{1}$ The combination of cisplatin and 5-flurouracil is considered standard therapy, ${ }^{2}$ although newer data suggest that the combination of cisplatin and paclitaxel may have equal efficacy with less toxicity. ${ }^{3}$ Response data for the use of single-agent paclitaxel in patients with head and neck cancer also are well established. ${ }^{4}$ In vitro studies combining paclitaxel with cisplatin demonstrated a synergistic interaction between these 2 agents, whereby paclitaxel inhibited platinum-DNA adduct repair. Studies also indicate that sequencing of these agents, with cisplatin given after paclitaxel, is crucial for such synergy. ${ }^{5}$

In addition to this synergistic effect, toxicity from the combination of cisplatin and paclitaxel also has influenced the sequencing of these 2 agents. In Phase I trials, more pronounced neutropenia was observed when cisplatin was given prior to paclitaxel. Pharmacologic data indicate that the increased toxicity probably is caused by a $25 \%$ decrease in paclitaxel clearance when cisplatin administration precedes that of paclitaxel. In a Phase I study of cisplatin plus paclitaxel, the dose-limiting toxicity was neutropenia. Other toxicities included mild-to-moderate neurotoxicity, which was more prominent in patients with heavy alcohol use or preexisting neuropathy. ${ }^{6}$

In an effort to augment the activity of 5-fluorouracil and cisplatin, paclitaxel was administered with these 2 agents in a Phase I/II pilot study at Wayne State University. ${ }^{7}$ That study was conducted to determine the feasibility, toxicities, and maximum tolerated dose for the combination of paclitaxel, cisplatin, and 5-fluorouracil in patients with recurrent, metastatic, or locoregionally advanced SCCHN. The overall response rate was $58 \%$, and the 1 -year survival rate was $37 \%$. The median overall survival was 6 months. Major toxicities were mucositis and neutropenia. Encouraged by these results, the Southwest Oncology Group (SWOG) investigators initiated a Phase II trial of paclitaxel, cisplatin, and 5-fluorouracil in patients with advanced or recurrent SCCHN in the cooperative group setting. The objectives of this trial were to determine the feasibility, efficacy, and toxicity of this triplet combination in a population whose poor general condition often is complicated by specific cancer morbidities.

\section{MATERIALS AND METHODS Eligibility}

Patients with histologically proven SCCHN, which was metastatic at diagnosis or had persisted, metastasized, or recurred after definitive surgery or radiation therapy, were eligible. Newly diagnosed patients with nonmetastatic disease were not eligible. Patients with both measurable and nonmeasurable disease were permitted to enter the study. Measurable disease was defined by using the Response Evaluation Criteria in Solid Tumors (RECIST). ${ }^{8}$ Prior chemotherapy for recurrent or newly diagnosed metastatic disease was not permitted. However, either 1 induction or adjuvant chemotherapy regimen or 1 concomitant chemoradiation regiment was permitted as long as 6 months had elapsed since the last course of chemotherapy. Participants were required to be at least age 18 years. When the study initially opened for enrollment on November 1, 2000, patients were required to have had a Zubrod performance status (PS) $\leq 2$. However, the study was closed temporarily in August 2001 for concerns regarding patient safety. When the study was reactivated on November 1, 2001, enrollment was restricted to patients with a Zubrod $\mathrm{PS} \leq 1$. All patients had to have adequate renal function, as documented by a serum creatinine level $\leq 1.5$ $\mathrm{mg} / \mathrm{dL}$ or a creatinine clearance of $\geq 50 \mathrm{cc}$ per minute. In addition, every patient had to have an absolute neutrophil count (ANC) $\geq 1500 \mu \mathrm{L}$, a platelet count $\geq 100,000 \mu \mathrm{L}$, a serum bilirubin level $\leq 2$ times the upper limit of normal (ULN), and alanine and aspartate aminotransferase levels $\geq 1.5$ times the ULN. Patients with sensory neuropathy greater than Grade 2 were not eligible. Patients who had uncontrolled hypertension, unstable angina, congestive heart failure, ventricular arrhythmias requiring medication, or myocardial infarctions within 6 months of enrollment were ineligible along with patients who had an active, systemic malignancy within 5 years of enrollment. No other concurrent radiation, hormone, or biologic therapies were permitted. The study was approved by the Institutional Review Boards at each participating institution. All patients provided informed consent.

\section{Treatment Plan}

Patients were premedicated with dexamethasone at a dose of $20 \mathrm{mg}$, diphenhydramine at a dose of $50 \mathrm{mg}$, and ranitidine at a dose of $50 \mathrm{mg}$ intravenously 30 minutes prior to paclitaxel administration. Paclitaxel $\left(135 \mathrm{mg} / \mathrm{m}^{2}\right)$ was infused over 3 hours on Day 1 prior to cisplatin. Cisplatin $\left(75 \mathrm{mg} / \mathrm{m}^{2}\right)$ was given over 30 minutes. Hydration and mannitol diuresis were given prior to cisplatin according to the standard guidelines set forth by each institution. After cisplatin, 5-fluorouracil (1000 $\mathrm{mg} / \mathrm{m}^{2}$ per day) was administered as a continuous infusion over 96 hours. Treatment cycles were repeated at 21-day intervals if complete recovery from toxicity occurred. 


\section{Treatment Evaluations and Dose Modifications}

Prior to enrollment, patients underwent a history and physical examination. Pretherapy laboratory studies included a complete blood cell count with differential count and platelet count (CDP) and serum chemistries. Renal function was monitored either by measuring serum creatinine levels or by calculating 24-hour clearance. Computed tomography scans or magnetic resonance images were obtained to establish baseline disease measurements prior to chemotherapy. Chemistries and renal function were monitored prior to each chemotherapy cycle. A CDP was drawn on Day 15 and on Day 1 of each subsequent cycle. Audiograms were recommended for any patient with hearing loss to document baseline hearing status prior to cisplatin administration.

The National Cancer Institute Common Toxicity Criteria (version 2.0) were used for the classification of adverse events. ${ }^{9}$ Dosage modifications were based on the nadir laboratory values of the preceding chemotherapy cycle. Prior to August 2001, chemotherapy was given subsequently if a patient's ANC was $\geq 1000 / \mu \mathrm{L}$ at the time of chemotherapy administration, and dosage adjustments were made to chemotherapy if nadir granulocyte counts were $\leq 500$ / $\mu \mathrm{L}$. Upon protocol reactivation in November 2001, hematologic recovery to an ANC $>1500 / \mu \mathrm{L}$ was required, and dosage adjustments were made if nadir granulocyte counts were $\leq 750 \mu \mathrm{L}$. Granulocyte-colony stimulating factor (G-CSF) was not administered to prevent neutropenia. Patients who experienced Grade 3 or 4 neutropenia had G-CSF ( $5 \mu \mathrm{L} / \mathrm{kg}$ per day) added to subsequent cycles of chemotherapy at the discretion of their prescribing physicians. G-CSF was given until the ANC recovered to $>10,000 / \mu \mathrm{L}$ after nadir and was discontinued 24 hours prior to the next chemotherapy dose.

\section{Response Criteria}

Response was evaluated according to RECIST criteria. Disease was assessed after every 2 cycles. Patients who achieved a complete response (CR) were removed from treatment after they received 3 additional cycles of chemotherapy. Otherwise, patients were treated until they developed disease progression. Patients who had only nonmeasurable disease were excluded from the response analysis.

\section{Statistical Considerations}

The main objective of this study was to assess the survival in patients with advanced or recurrent SCCHN when they were treated with the triplet combination of paclitaxel, cisplatin, and 5-fluorouracil discussed above. The regimen was considered unpromising if the true median survival was $\leq 6$ months and was of considerable interest if the median survival was $\geq 9$ months. With 65 patients accrued over 12 months and an additional 12 months of follow-up, the power of a 1-sided level .05 exponential score test was .90. If the observed median survival was $\geq 7.5$ months, then the regimen was to be considered for further study.

Secondary objectives were to assess response in the subset of patients who had measurable disease, progression-free survival, and toxicity. Assuming that 55 patients had measurable disease, this number was sufficient to estimate the probability of response (confirmed and unconfirmed, complete and partial) to within $\pm 13 \%$ (95\% confidence interval [95\% CI]). Sixty-five patients were sufficient to estimate the probability of any specific adverse events to within $\pm 12 \%$ (95\% CI). Any adverse event that occurred with at least $5 \%$ probability was likely to have been seen once (96\% chance). In addition, 65 patients were sufficient to estimate progression-free survival at any selected time points, namely, 1 year to 2 years, to within $\pm 12 \%$ (95\% CI). Median overall survival and median progression-free survival were derived from estimates that were obtained by using the method of Kaplan and Meier. ${ }^{10}$

\section{RESULTS \\ Patient Characteristics}

From November 1, 2000 to May 15, 2003, 78 patients were registered from 34 participating institutions. Two patients were ineligible because they had insufficient documentation. On August 14, 2001, the study was closed temporarily because of concerns regarding patient safety. The protocol was revised to allow for better tolerance of treatment, which included changing the requirements for chemotherapy dosing based on granulocyte recovery and changing the Zubrod PS eligibility from $\leq 2$ to $\leq 1$.

Of the 76 eligible patients, 69 patients (91\%) had measurable disease, and 7 patients (9\%) had only nonmeasurable disease. Response was not determinable in 11 patients who had measurable disease because of inadequate assessment (10 patients) or early death (1 patient). Patient characteristics are noted in Table 1.

\section{Toxicity}

All 76 eligible patients were evaluated for adverse events. Thirty-two patients $(42 \%)$ were hospitalized during the course of this study for a total of 40 hospitalizations. Two patients were admitted on 3 different occasions, and 5 patients were hospitalized 
TABLE 1

Patient Characteristics

\begin{tabular}{|c|c|c|}
\hline Characteristic & $\begin{array}{l}\text { No. of } \\
\text { patients }\end{array}$ & $\begin{array}{l}\text { Percent of } \\
\text { patients }\end{array}$ \\
\hline \multicolumn{3}{|l|}{ Gender } \\
\hline Male & 61 & 80 \\
\hline Female & 15 & 20 \\
\hline \multicolumn{3}{|l|}{ Age, y } \\
\hline Median & 59.5 & \\
\hline Range & $29.5-77.4$ & \\
\hline \multicolumn{3}{|l|}{ Zubrod performance status } \\
\hline 0 & 21 & 28 \\
\hline 1 & 50 & 66 \\
\hline 2 & 5 & 7 \\
\hline \multicolumn{3}{|l|}{ Prior treatment } \\
\hline Surgery only & 2 & 3 \\
\hline RT only & 4 & 5 \\
\hline Surgery plus RT & 57 & 72 \\
\hline $\begin{array}{l}\text { Chemotherapy plus } \\
\text { (RT with or without surgery) }\end{array}$ & 10 & 12 \\
\hline None or unknown & 3 & 8 \\
\hline \multicolumn{3}{|l|}{ Sites of disease at baseline } \\
\hline Locoregional only & 25 & 32 \\
\hline Distant only & 20 & 27 \\
\hline Both & 31 & 41 \\
\hline
\end{tabular}

twice. The primary reason for hospitalization was dehydration related to Grade 3 or 4 mucositis/esophagitis, followed by febrile neutropenia with or without infection.

Six treatment-related deaths occurred and are reported in Table 2. Common adverse events are recorded in Table 3. Thirty-three patients (43\%) experienced a Grade 3 adverse event, and 28 patients (37\%) experienced a Grade 4 adverse event. The most commonly reported Grade 3 or worse toxicity was neutropenia. Eleven patients (14\%) developed Grade 3 or worse infection with neutropenia. Twenty patients (26\%) were given G-CSF with all subsequent cycles of chemotherapy. Six patients $(8 \%)$ required transfusions of packed red blood cells, and 13 patients (17\%) were treated with erythropoietin. Grade 4 thrombocytopenia was observed in 2 patients, both of whom were given platelet transfusions.

Of the 5 patients who received $>6$ cycles of chemotherapy, 3 patients died from infection during their last cycle of treatment. All 5 of those patients developed Grade 3 or 4 asthenia, 2 experienced Grade 4 motor neuropathy, and 3 developed Grade 2 motor and sensory neuropathies.

\section{Treatment and Tolerance}

In total, 286 cycles of chemotherapy were administered to 76 eligible patients during the course of this
TABLE 2

Treatment-Related Deaths

\begin{tabular}{lll}
\hline Cause of death & $\begin{array}{l}\text { No. of } \\
\text { patients }\end{array}$ & $\begin{array}{l}\text { Zubrod } \\
\text { PS }\end{array}$ \\
\hline $\begin{array}{l}\text { Infection } \\
\quad \text { Sepsis with ANC unknown }\end{array}$ & 2 & 2 and 2 \\
$\quad$ Sepsis with neutropenia & 2 & 0 and 1 \\
Other & 1 & 1 \\
$\quad$ Inanition & 1 & 1 \\
$\quad$ Pulmonary edema & \\
\hline PS indicates performance status; ANC, absolute neutrophil count. \\
\hline
\end{tabular}

study. There were 132 full-dose cycles (46\%) and 154 reduced-dose cycles (54\%). The median number of chemotherapy cycles delivered was 4 (range, 1-10 cycles). Thirteen patients (17\%) received only 1 cycle of chemotherapy, 58 patients $(76 \%)$ received between 2 and 6 cycles of chemotherapy, and 5 patients (7\%) received $>6$ cycles of chemotherapy. Of the patients who received $>6$ cycles, 2 patients had a CR, and 3 patients had stable disease with palliation of pain from larger tumor burdens. Dosage reductions that were required during chemotherapy administration and adverse events that prompted dosage reductions are summarized in Table 4.

\section{Response to Treatment}

Of the 69 patients who were evaluable for response, 5 patients (7\%) attained CRs, 2 of which were unconfirmed according to the RECIST criteria. Twentythree patients (33\%) had partial responses, including 14 confirmed and 9 unconfirmed responses. The overall response rate was $41 \%$ (95\% CI, $29-53 \%)$.

Progression-free survival and overall survival are illustrated in Figure 1 and Figure 2, respectively. The median survival was 10 months $(95 \%$ CI, $7-12$ months). The estimate 1-year survival rate was $42 \%$ (95\% CI, 31-53\%). The median progression-free survival was 4 months (95\% CI, 3-5 months). The median time to follow-up for patients who remained alive was 25 months.

\section{DISCUSSION}

Historically, the median survival for patients with advanced/recurrent SCCHN who received palliative chemotherapy has been 6 months. ${ }^{1,2}$ SWOG 0007 was designed to show an improvement in overall survival, and our results demonstrated a positive outcome with a median survival of 10 months. Seventy-six patients were enrolled on this study; and, to our knowledge, it is the largest reported, nonrandomized Phase II experience in patients with metastatic or locally advanced head and neck cancers. 
TABLE 3

Common Adverse Events

\begin{tabular}{lccccc}
\hline & \multicolumn{5}{c}{ No. of patients (\%) } \\
\cline { 2 - 6 } Adverse Event & Grade 1 & Grade 2 & Grade 3 & Grade 4 & Grade 5 \\
\hline Anemia & $32(42)$ & $28(37)$ & $6(8)$ & $1(1)$ & 0 \\
Thrombocytopenia & $17(22)$ & $2(3)$ & 0 & $2(3)$ & 0 \\
Leucopenia & $14(18)$ & $14(18)$ & $23(30)$ & $8(11)$ & 0 \\
Neutropenia & $10(13)$ & $11(14)$ & $20(26)$ & $16(21)$ & 0 \\
Febrile neutropenia & 0 & 0 & $2(3)$ & 0 & 0 \\
Infection with neutropenia & 0 & 0 & $6(8)$ & $1(1)$ & $1(1)$ \\
Respiratory infection with neutropenia & 0 & 0 & $2(3)$ & 0 & $1(1)$ \\
Esophagitis/dysphagia & $10(13)$ & $12(16)$ & $10(13)$ & $5(7)$ & 0 \\
Mucositis/stomatitis & $8(11)$ & $24(32)$ & $19(25)$ & $7(9)$ & 0 \\
Diarrhea & $14(18)$ & $9(12)$ & $4(5)$ & $2(3)$ & 0 \\
Nausea & $15(20)$ & $22(29)$ & $15(20)$ & 0 & 0 \\
Sensory neuropathy & $14(18)$ & $3(4)$ & $3(4)$ & 0 & 0 \\
Motor neuropathy & $4(5)$ & $3(4)$ & $1(1)$ & $2(3)$ & 0 \\
Asthenia & $18(24)$ & $28(37)$ & $13(17)$ & $2(3)$ & 0 \\
Renal/creatinine & $8(10)$ & $7(9)$ & $1(1)$ & 0 & 0 \\
\hline
\end{tabular}

TABLE 4

Dosage Reductions for Subsequent Cycles of Chemotherapy

\begin{tabular}{|c|c|c|c|c|}
\hline Drug dosages reduced & $\begin{array}{l}\text { Total No. } \\
\text { of patients }\end{array}$ & Adverse event & No.* & $\begin{array}{l}\text { No. of patients who } \\
\text { required omission of } \\
\text { drug from regimen }\end{array}$ \\
\hline Paclitaxel/5-FU/cisplatin & 27 & $\begin{array}{l}\text { Grade } 3 / 4 \text { neutropenia } \\
\text { Grade } 2 / 4 \text { mucositis } \\
\text { Grade } 3 / 4 \text { esophagitis } \\
\text { Grade } 3 \text { nausea } \\
\text { Grade } 2 \text { renal/creatinine } \\
\text { Grade } 4 \text { thrombocytopenia } \\
\text { Grade } 3 / 4 \text { motor neuropathy }\end{array}$ & $\begin{array}{l}27 \\
9 \\
5 \\
15 \\
4 \\
2 \\
3\end{array}$ & 0 \\
\hline Paclitaxel/cisplatin & 2 & $\begin{array}{l}\text { Grade } 3 \text { diarrhea } \\
\text { Grade } 3 \text { neutropenia }\end{array}$ & $\begin{array}{l}2 \\
2\end{array}$ & 0 \\
\hline 5-FU only & 17 & $\begin{array}{l}\text { Grade } 3 / 4 \text { mucositis } \\
\text { Grade } 3 / 4 \text { diarrhea } \\
\text { Grade } 3 / 4 \text { esophagitis }\end{array}$ & $\begin{array}{l}17 \\
4 \\
10\end{array}$ & 3 \\
\hline Paclitaxel/cisplatin & 3 & Grade 3 sensory neuropathy & 3 & 0 \\
\hline Cisplatin only & 2 & Grade $2 / 3 \mathrm{renal} /$ creatinine & 2 & 2 \\
\hline
\end{tabular}

5-FU indicates 5-fluorouracil.

* The number of patients who experienced a particular adverse event that led to dosage reductions for $\geq 1$ drugs. Patients who required reductions of only 1 or 2 drug dosages either had 1 drug eliminated from the treatment regimen prior to (i.e., cisplatin in the case of paclitaxel/5-FU or 5-FU in the case of paclitaxel/cisplatin) or required dosage reductions specific only to 1 drug (i.e., cisplatin and renal toxicity).

Table 5 summarizes data from several randomized and nonrandomized trials among patients with advanced/recurrent SCCHN. The median survival of 10 months observed in the current study surpassed our predetermined cut-off level of interest and was comparable to the survival observed with other platinum-based and paclitaxel-based regimens ${ }^{3,11-14}$ and with single-agent paclitaxel administered at a dose of $250 \mathrm{mg} / \mathrm{m}^{2}$ over 24 hours. $^{4}$
Objective response rates in the current study also were similar to other studies that used triplet combinations. ${ }^{14-16}$ SWOG 0007, however, enrolled more patients with distant metastatic disease (67\%) compared with other nonrandomized trials. Thus, our results are encouraging, because published data indicate that chemotherapy may be more effective in patients with locoregional recurrence than in patients with metastatic disease. ${ }^{17,18}$ 


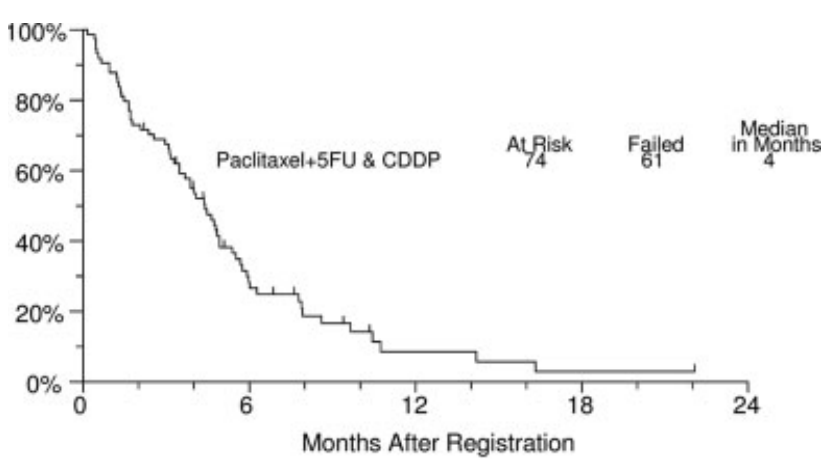

FIGURE 1. Progression-free survival is illustrated by treatment arm. $5 \mathrm{FU}$ indicates 5-fluorouracil; CDDP, cisplatin.

The use of induction chemotherapy is becoming more favorable for the treatment of patients with SCCHN, with published trials demonstrating a survival benefit from regimens of combined cisplatin and 5-fluorouracil. ${ }^{19-21}$ Newer data show an improvement in survival when taxanes are added to cisplatin and 5-fluorouracil in the neoadjuvant setting. This improvement in survival may be caused by the pharmacologic effect of the taxanes or by specific prognostic factors. ${ }^{22}$ Hitt et al. ${ }^{23}$ demonstrated an improvement in CR rate, time to treatment failure, and overall survival when paclitaxel was added to cisplatin and 5-flurouracil compared with cisplatin and 5fluorouracil. Similarly, the European Organization for Research and Treatment of Cancer randomized patients with nonresectable, locally advanced SCCHN to receive cisplatin and 5-fluorouracil versus cisplatin, 5-fluorouracil, and docetaxel as neoadjuvant chemotherapy prior to definitive radiation therapy. ${ }^{24}$ The triplet study arm had statistically significant improvements in response rate, progressionfree survival, and overall survival with fewer toxic deaths.

Unlike SWOG 0007, the studies described above treated a different patient population (i.e., patients who previously had not received chemotherapy or radiation therapy, patients with a PS of 0 or 1). In general, patients with recurrent SCCHN who receive combination chemotherapy and who have a PS $\leq 1$ have more favorable outcomes ${ }^{25}$ including patients with a PS $\leq 1$ who are older than 70 years. ${ }^{26}$ Nearly $75 \%$ of the patients enrolled in our current study had a PS $\geq 1$. Five patients with a PS of 2 either died or suffered Grade 4 adverse events, prompting revision of the study to include only patients with a PS $\leq 1$. Despite this change, 4 additional treatmentrelated deaths occurred, suggesting that triplet combinations that use taxanes, cisplatin, and 5 -fluorouracil should be administered to only the healthiest patients.

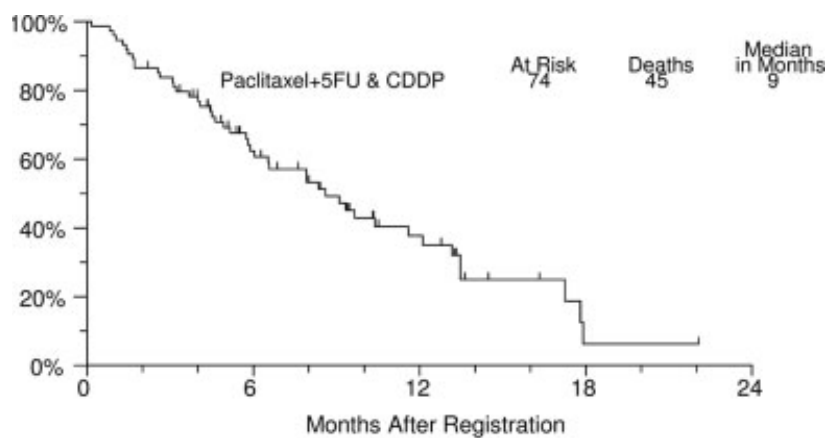

FIGURE 2. Overall survival is illustrated by treatment arm. 5FU indicates 5-fluorouracil; CDDP, cisplatin.

Toxicity was also a major problem. Seventeen percent of the eligible patients received only 1 cycle of chemotherapy, and almost $75 \%$ of patients required dosage reductions with subsequent cycles of chemotherapy. In addition, nearly $50 \%$ of patients were hospitalized on 1 or more occasion. Although the study was revised with more stringent guidelines for chemotherapy administration with respect to hematologic parameters, the overwhelming number of hospitalizations and dosage reductions related to mucositis, esophagitis, and neutropenia indicate that the dosages of 5 -fluorouracil, cisplatin, and paclitaxel in our study were too high for this comprised population, which included a large number of patients with metastatic disease. Of all agents, 5-fluorouracil demanded the most dosage reductions, with $>60 \%$ of patients requiring 1 or more dosage adjustments. Because progression-free survival was shortened by so many toxic events, we know now that the 5-fluorouracil dose should have been much lower than what was prescribed in our study. Hitt et al. ${ }^{27}$ reported that the recommended dose of 5-fluorouracil in the combination of paclitaxel, cisplatin, and 5fluorouracil as induction chemotherapy is $500 \mathrm{mg} /$ $\mathrm{m}^{2}$. This dosage did not have a negative impact on response and allowed for significantly less toxicity.

The rate of Grade 3 and 4 neutropenia reported in our study was $47 \%$. This degree of neutropenia may be not only dose-related but also scheduledependent. In the current study, both paclitaxel and cisplatin were administered on Day 1 followed by a 96-hour continuous infusion of 5-fluorouracil. Results from a dose-finding study that was conducted in Italy showed that paclitaxel at a dose of $160 \mathrm{mg} /$ $\mathrm{m}^{2}$ on Day 1 , cisplatin at a dose of $25 \mathrm{mg} / \mathrm{m}^{2}$ on Days 1 through 3 , and 5 -fluorouracil at a dose of $250 \mathrm{mg} / \mathrm{m}^{2}$ on Days 1 through 3 can be administered safely without growth factor support. ${ }^{15}$ It is possible that high-dose cisplatin inhibits the clearance of paclitaxel even if paclitaxel is administered 


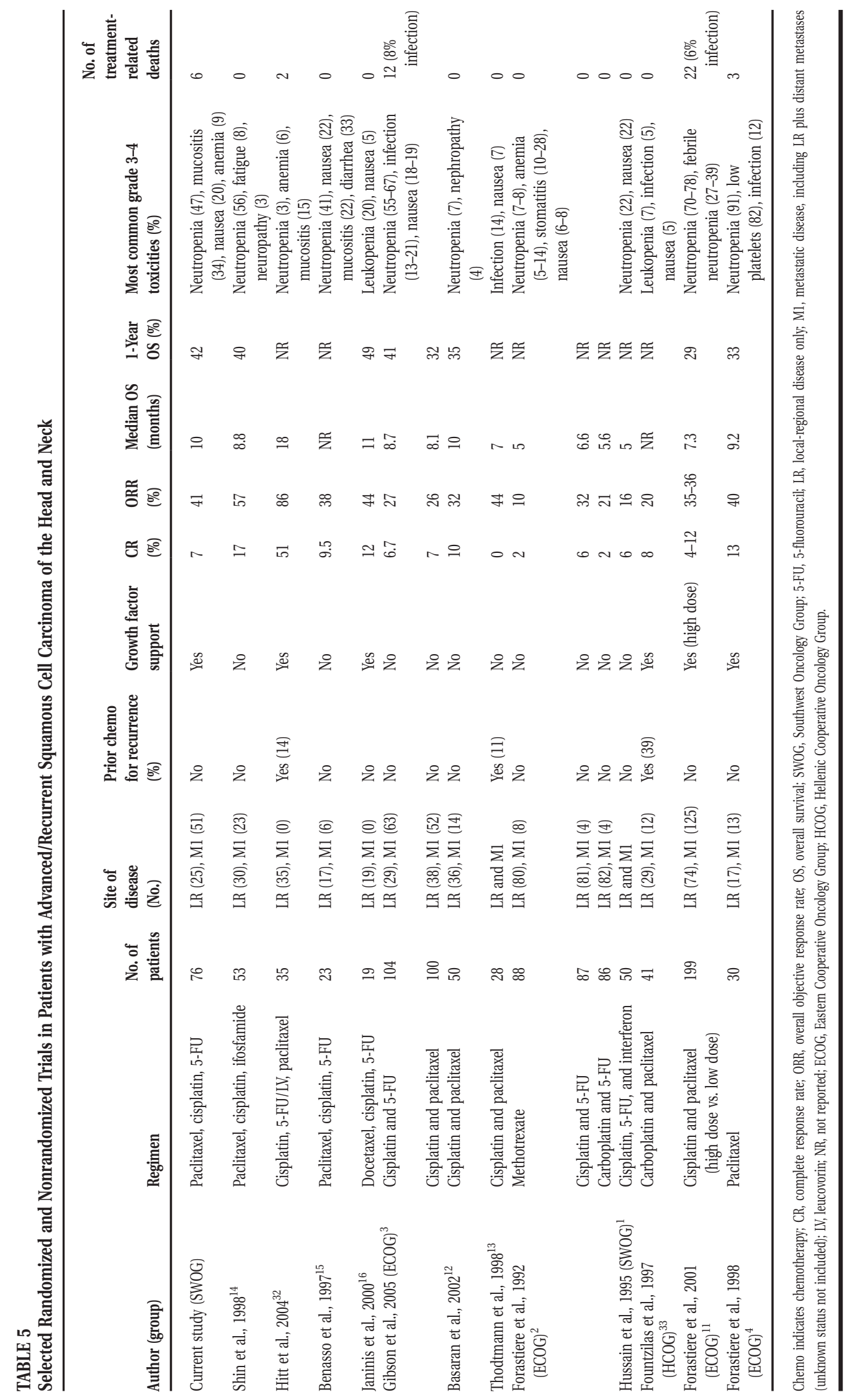


prior to cisplatin. High-dose cisplatin administered 1 day after paclitaxel also is associated with lower rates of Grade 4 neutropenia. ${ }^{27}$ Thirty percent of the patients on SWOG 0007 who were treated with 2 or more cycles of chemotherapy required support with G-CSF. Staar et al. ${ }^{28}$ reported a reduction in locoregional control when G-CSF was administered prophylactically to patients who were receiving chemoradiation for locally advanced SCCHN. Whether this had any impact in terms of disease control in our study is not known, because our patients did not receive concomitant radiation therapy.

Neurotoxicity also was a problem in patients who received $\geq 6$ cycles of chemotherapy. Moreover, patients who received $\geq 450 \mathrm{mg} / \mathrm{m}^{2}$ of cisplatin required dosage reductions for either sensory or motor neuropathies. Because paclitaxel also is associated with neurotoxicity, it would have been reasonable to substitute carboplatin for cisplatin once patients had received a cumulative cisplatin dose of $400 \mathrm{mg} / \mathrm{m}^{2}$ in an effort to reduce neurotoxic effects. Such data have been reported in patients with ovarian cancer who received prolonged courses of platinum and paclitaxel..$^{29,30}$ Similarly, an editorial in The Journal of Clinical Oncology by Takimoto and Rowinksy sited several studies in various solid tumor types that demonstrated improvements in response rates when the dose intensity of paclitaxel was increased; however, toxicity also was enhanced, and improvements in overall survival were negligible. ${ }^{31}$

In conclusion, the combination of paclitaxel, cisplatin, and 5-fluorouracil had similar efficacy but increased toxicity compared with standard treatment regimens in patients with advanced or recurrent SCCHN. Given the significant hematologic and nonhematologic toxicities, this regimen may not be appropriate for all patients in the palliative setting. In the alternative, this combination may prove to be useful as neoadjuvant therapy, as demonstrated by the high number of responders in our study who had widespread disease.

\section{REFERENCES}

1. Hussain M, Benedetti J, Smith RE, et al. Evaluation of 96 hour infusion fluorouracil plus cisplatin in combination with alpha interferon for patients with advanced squamous cell carcinoma of the head and neck. Cancer. 1995;76:1233-1237.

2. Forastiere AA, Metch B, Schuller DE, et al. Randomized comparison of cisplatin plus fluorouracil and carboplatin plus fluorouracil versus methotrexate in advanced squamous cell carcinoma of the head and neck: a Southwest Oncology Group study. J Clin Oncol. 1992;10:1245-1251.

3. Gibson M, Yi L, Murphy B, et al. Phase III evaluation of cisplatin and 5-fluorouracil versus cisplatin and paclitaxel in advanced head and neck cancer (E1395): an intergroup trial of the Eastern Cooperative Oncology Group. J Clin Oncol. 2005;23:3562-3567.

4. Forastiere AA, Shank D, Neuberg D, et al. Final report of a Phase II evaluation of paclitaxel in patients with advanced squamous cell carcinoma of the head and neck: an Eastern Cooperative Oncology Group trial (PA390). Cancer. 1998; 82:2270-2274.

5. Parker RJ, Dabholkar MD, Lee KB, et al. Taxol effect on cisplatin sensitivity and cisplatin cellular accumulation in human ovarian cancer cells. J Natl Cancer Inst. 1993;15: 83-88.

6. Rowinsky EK, Gilbert MR, McGuire WP, et al. Sequences of taxol and cisplatin: a Phase I and pharmacologic study. J Clin Oncol. 1991;9:1692-1703.

7. Hussain M, Gadgeel S, Kucuk O, et al. Paclitaxel, cisplatin, 5-fluorouracil in patients with advanced/recurrent squamous cell carcinoma of the head and neck. Cancer. 1999; 86:2364-2369.

8. Therasse P, Arbuck S, Eisenhauer E, et al. New guidelines to evaluate the response to treatment in solid tumors. European Organization for Research and Treatment of Cancer, National Cancer Institute of the United States, National Cancer Institute of Canada. J Natl Cancer Inst. 2000;92: 205-216.

9. National Cancer Institute. Investigator's handbook: a manual for participants in clinical trials of investigational agents sponsored by DCTD, NCI. Bethesda: National Cancer Institute, 1993.

10. Kaplan EL, Meier P. Nonparametric estimation from incomplete observations. J Am Stat Assoc. 1958;53:457-481.

11. Forastiere AA, Leong T, Rowinsky E, et al. Phase III comparison of high-dose paclitaxel + cisplatin + granulocyte colony-stimulating factor versus low-dose paclitaxel + cisplatin in advanced head and neck cancer: Eastern Cooperative Oncology Group Study E1393. J Clin Oncol. 2001; 19:1088-1095.

12. Basaran M, Bavbek SE, Gullu I, et al. A Phase II study of paclitaxel and cisplatin combination chemotherapy in recurrent or metastatic head and neck cancer. J Chemother. 2002;14:207-213.

13. Thodtmann F, Theiss F, Kemmerich M, et al. Clinical Phase II evaluation of paclitaxel in combination with cisplatin in metastatic or recurrent squamous cell carcinoma of the head and neck. Ann Oncol. 1988;9:335-337.

14. Shin DM, Glisson BS, Khuri FR, et al. Phase II trial of paclitaxel, ifosfamide, and cisplatin in patients with recurrent head and neck squamous cell carcinoma. J Clin Oncol. 1998;16:1325-1330.

15. Benasso M, Numico G, Rosso R, et al. Chemotherapy for relapsed head and neck cancer: paclitaxel, cisplatin, and 5fluorouracil in chemotherapy-naive patients. A dose finding study. Semin Oncol. 1997;24:S19-46-S19-50.

16. Janinis J, Papadakou M, Xidakis E, et al. Combination chemotherapy with docetaxel, cisplatin, and 5-fluorouracil in previously treated patients with advanced/recurrent head and neck cancer: a Phase II feasibility study. Am J Clin Oncol. 2000;23:128-131.

17. Recondo G, Armand JP, Tellez-Bernal E, et al. Recurrent and/or metastatic head and neck squamous cell carcinoma: a clinical univariate and multivariate analysis of response and survival with cisplatin-based chemotherapy. Laryngoscope. 1991;101:494-501.

18. Schornagel JH, Verweij J, de Mulder PH, et al. Randomized Phase III trial of edatrexate versus methotrexate in patients with metastatic and/or recurrent squamous cell carcinoma 
of the head and neck: a European Organization for Research and Treatment of Cancer Head and Neck Cancer Cooperative Group study. J Clin Oncol. 1995;13:1649-1655.

19. Paccagnella A, Orlando A, Marchiori C, et al. Phase III trial of initial chemotherapy in Stage III or IV head and neck cancers: a study by the Gruppo di Studio sui Tumori della Testa e del Collo. J Natl Cancer Inst. 1994;86:265-272.

20. Domenge C, Hill C, Lefebvre JL, et al. Randomized trial of neoadjuvant chemotherapy in oropharyngeal carcinoma. Br J Cancer. 2000;83:1594-1598.

21. Pignon JP, Bourhis J, Domenge C, et al. Chemotherapy added to locoregional treatment for head and neck squamous-cell carcinoma: three meta-analyses of updated individual data. MACH-NC Collaborative Group. Meta-Analysis of Chemotherapy on Head and Neck Cancer. Lancet. 2000;355:949-950.

22. Pignon JP, Syz N, Posner M, et al. Adjusting for patient selection suggests the addition of docetaxel to 5 -fluorouracil-cisplatin induction therapy may offer survival benefit in squamous cell cancer of the head and neck. Anticancer Drugs. 2004;15:331-340.

23. Hitt R, Lopez-Pousa A, Martinez-Trufero J, et al. Phase III study comparing cisplatin, plus 5-fluorouracil to paclitaxel, cisplatin, and 5-flurouracil induction chemotherapy followed by chemoradiotherapy in locally advanced head and neck cancer. J Clin Oncol. 2005;23:8636-8645.

24. Vermorken JB, Remenar E, van Herpen J, et al. Standard cisplatin/infusional 5-fluorouracil versus docetaxel plus cisplatin/infusional 5-fluoruracil as neoadjuvant chemotherapy for nonresectable locally advanced squamous cell carcinoma of the head and neck: a Phase III trial of the EORTC Head and Neck Cancer Group (EORTC 24971). Proc Am Soc Clin Oncol. 2004;5508:490. Abstract.
25. Pivot X, Niyikiza C, Poissonnet G, et al. Clinical prognostic factors for patients with recurrent head and neck cancer: implications for randomized trials. Oncology. 2001;61:197204.

26. Argiris A, Li Y, Murphy BA, et al. Outcome of elderly patients with recurrent or metastatic head and neck cancer treated with cisplatin-based chemotherapy. J Clin Oncol. 2004;22:262-268.

27. Hitt R, Paz-Ares L, Brandariz A, et al. Induction chemotherapy with paclitaxel, cisplatin, and 5-fluorouracil for squamous cell carcinoma of the head and neck: long-term results of a Phase II trial. Ann Oncol. 2002;13:1665-1673.

28. Staar S, Rudat V, Stuetzer H, et al. Intensified hyperfractionated accelerated radiotherapy limits the additional benefit of simultaneous chemotherapy-results of a multicenter randomized German trial in advanced head-and-neck cancer. Int J Radiat Oncol Biol Phys. 2001;50:1161-1171.

29. du Bois A, Luck HJ, Meier W, et al. A randomized trial of cisplatin/paclitaxel versus carboplatin/paclitaxel as firstline treatment of ovarian cancer. J Natl Cancer Inst. 2003 95:1320-1329.

30. Alberts DS. Carboplatin versus cisplatin in ovarian cancer. Semin Oncol. 1995;22:88-90.

31. Takimoto C, Rowinsky E. Dose-intense paclitaxel: deja vu all over again? J Clin Oncol. 2003;21:2810-2814.

32. Hitt R, Jimeno A, Millan JM, et al. Phase II trial of dose-dense paclitaxel, cisplatin, and 5-fluorouracil, and leucovorin with filgrastim support in patients with squamous cell carcinoma of the head and neck. Anticancer Drugs. 2004;15:331-340.

33. Fountzilas G, Athanassiadis A, Samantas E, et al. Paclitaxel and carboplatin in recurrent or metastatic head and neck cancer: a Phase II study. Semin Oncol. 1997;24(Suppl 2): S2-65-S2-67. 